\title{
MKWI 2018 vom 6. bis 9. März "Data driven X - Turning Data into Value“
}

Seit im Jahr 2000 erstmals die Multikonferenz Wirtschaftsinformatik in Siegen stattfand, fördert die MKWI alle zwei Jahre in Form von Teilkonferenzen, Tutorials, Workshops, Panels und zentralen Vorträgen den Dialog zwischen Wissenschaft und Praxis. 2018 steht die MKWI in Lüneburg unter dem Motto „Data driven X - Turning Data into Value“ und adressiert damit eine für Unternehmen und die öffentliche Verwaltung hoch aktuelle und potenzialträchtige Frage: wie die immer noch exponenziell wachsenden Datenbestände genutzt werden können.

\section{Teilkonferenzen}

Die MKWI setzt auf ein vielfältiges Spektrum an Teilkonferenzen, die innovative Themen der WI aus Sicht von Wissenschaft und Praxis diskutieren. Die Multi-Konferenz Wirtschaftsinformatik 2018 ist in 28 Teilkonferenzen untergliedert.

\section{Weitere Formate}

Neben der eigentlichen Konferenz erwarten die Teilnehmer zahlreiche weitere Formate wie Tutorials, Workshops, Praxisforen und Panels.

Weitere Informationen insbesondere zu den Teilkonferenzen und zur Anmeldung finden Sie unter: http://mkwi2018. leuphana.de/

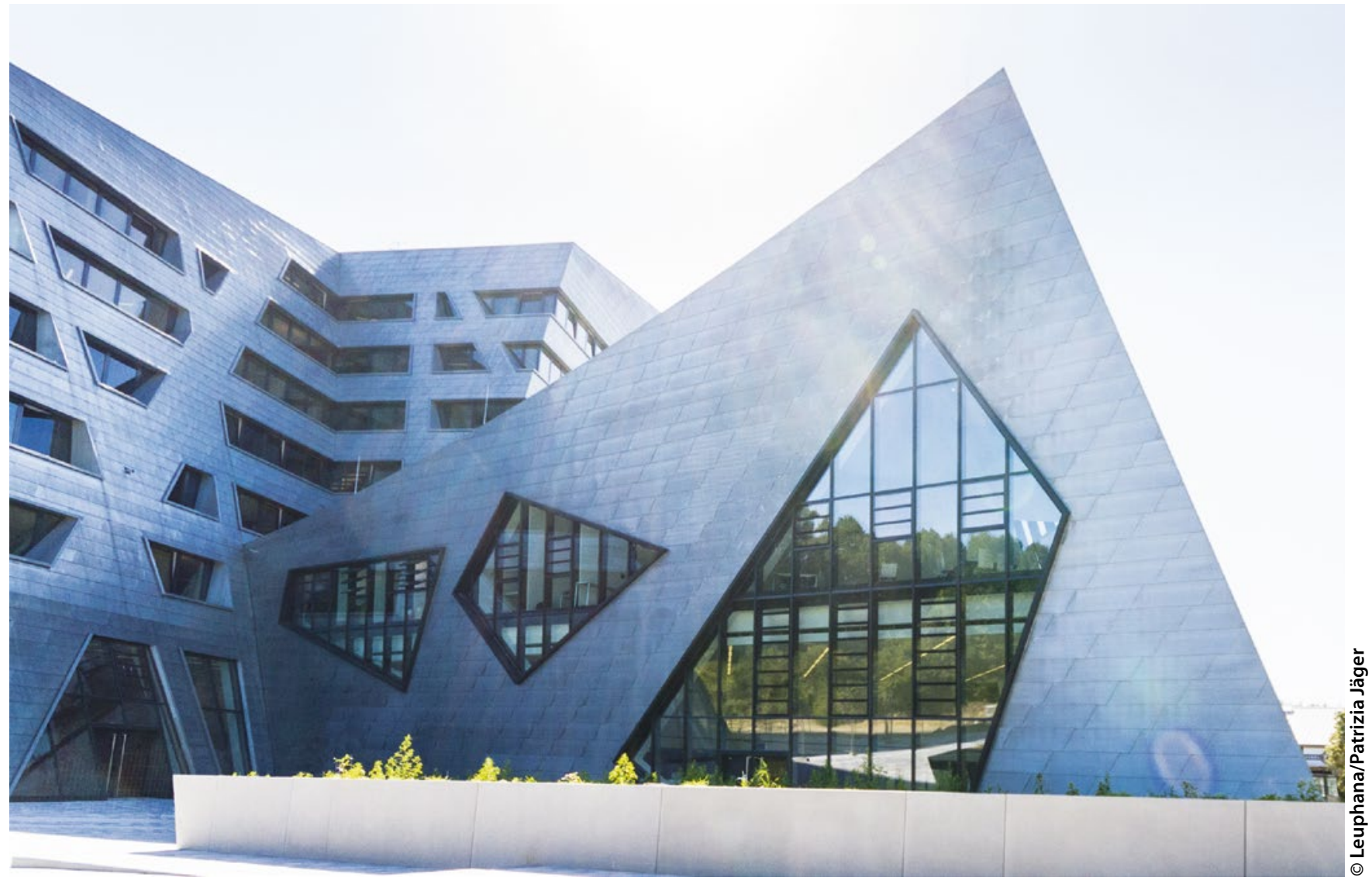

Zentralgebäude der Leuphana Universität. 